\title{
Determinants of Students Tertiary Level Academic Performance in Ethiopia "A Case in University of Gondar"
}

\author{
TADESSE WUDU ABATE \\ Faculty of Business and Economics, Department of Economics, Woldia University, Ethiopia, \\ Tadesse Wudu Abate, Woldia University, PO box 245, Ethiopia \\ SHEMSEDIN ABDU DAWUD \\ Lecturer of Economics at Mekdela Amba University
}

\begin{abstract}
This study is conducted to investigate the determinants of students' academic performance in university of Gondar using logstic regression approach. For the successful accomplishment of the research, primary data collected from 112 sampled students has been analyzed using both descriptive and econometrics methods. With this regard if there is a unit increment in students effort measured in number of hour spend in studying, there is corresponding rise of CGPA by 0.093 holding other explanatory variables. From the study result it is observed students who actually spend more of their time in studying score higher than those who do not, this is consistent with our initial hypothesis. The other variable which explains the academic performance of the students is gender where the proportion is in favor of male students. The study indicates that male students have more chance of scoring than females students. Variables like monthly income, age, home town and access to computer have no significant effect on the dependent variable in our study.
\end{abstract}

Keywords: Logit model, Students' academic performance, University of Gondar

DOI: $10.7176 / \mathrm{JEP} / 11-22-04$

Publication date:August $31^{\text {st }} 2020$

\section{Introduction}

\subsection{Background of the study}

According to the theory of human capital developed by Becker (1964) and, formal education is one of the factors leading to the development of the population's productive potential and affecting a country's economic growth. This means, as Elinah (2006) points out, that students constitute a country's key social capital, with the growth of the nation depending on the educational climate. This reflects the substantial public expenditure incurred by countries to fund the various educational levels according to Jacobs and Glen (2011) and the shift in the university education model promoted by various European countries, including Spain, through the Bologna Process, which encourages students to acquire the skills and skills needed to join the job market, as emerged from Mart.

The Universities Admission Center (2006) notes that tertiary institutions in Austria have found that the best sing le indicator of tertiary performance for most tertiary courses is placement rank based on the overall academic ach ievement of a student. The researcher agrees with the scholars that admission points influence, academic perfor mance at universities. According to the Uganda Universities and Other Tertiary Institutions Act (2001), the crite rion for university entry is the admission points obtained from A' levels, Diploma points and Mature Age points.

In any case, in spite of the endeavors made, the European Union part states a tall school drop-out rate concurring to the European Commission (2011). Specifically in Spain, the scholastic drop out and disappointment rate of college understudies come to $35 \%$ on normal, aimed the 2004-2009 periods concurring to information given by the service of instruction and the national measurements organized. The continuation of this circumstance may lead to an increment with in the unit etched of a graduate and the open investing put aside for a college education. Over the final three decades, there has been in Portugal a quite huge open speculation with in the school frame work and the usage of viable obligatory instructions. Open consumption in instruction expanded from $1.5 \%$ of GDP in 1974 to 5.5\% in 2001. These changes come besides the democratization of school encounter. The students' enrolments in Portuguese colleges expand from 7\% to 53\% between the years 1974 and 2004.

In show disdain toward of this noteworthy development Portugal remains one of the EU nations with reduced number of graduates and so the increment with in the number of students in higher institutions could be a national objective sought after by institutions arrangement. However in show disdain toward of all the government and parents venture in children instruction. School disappointment may be major issues that influence all levels of instructions. The serve of instruction reports that essential instruction maintenance and school dropouts at the conclusion of obligatory instruction rates are still higher in Ethiopia compared to other European countries.

In recent years, our country's observed facts shows that the number of graduated students and their capacity to be hired in any organization is unbalanced. Those students who graduated with the highest CGPA, which is 
proxy variable for students performance, are highly demanded by any governmental and non-governmental organizations. So identifying the main factors which affects the performance of students at university level is important to enable the students to have qualified educational capacity. As stated by previously conducted research papers all over the world, school performance is determined by a number of factors such as family background, student's entrant score, and level of family income, age, gender and e.t.c.

University of Gondar, which is one of the first generation universities in Ethiopia, has a vision to be a center of excellence in the heart of Ethiopia through keeping on quality of student's academic performance. However many reports by the academic deans have noted that even though some students perform highly, there are also some students who do not perform well.

It is not yet known why some students fail to attain the standards expected of them due to lack of sufficient research in the case of Gondar University as to what factors affect academic performance of the students. This research would therefore like to identify the factors affecting academic performance of undergraduate students of Gondar University by considering variables like access to computer, age, gender, study hours home town and money sent to students from their family. This study is unique from previous studies by incorporating up-to date variable of the number of hours spend on social Medias (like face book, twitter, viber and whatsapp and etc) in to the model.

\section{Review of Related Literatures}

The theory adapted for this analysis was derived from the input-output model of the System theory developed by Ludwig Von Bertalanffy in 1956. According to Koontz and Weihrich (1988) the theory postulates that there is no organized enterprise in a vacuum; it depends on its setting in which it is formed. We add that the company receives the inputs from the environment and then converts them into outputs. The students (Inputs) are admitted to the university, with various entry points, from different social economic backgrounds and from different school backgrounds, as adapted in this study when they enter the university system, the university administration guides them into the teaching and learning process and the students' success is seen in their academic performance.

Faroug et a (2011) lstates that organizations were highly represented as absorbers, processors, and generators, and that the structure of the organization could be conceived as composed of many interdependent components. According this study, device proponents have acknowledged that a shift in any aspect within the organization impacts on the other components of the structure or subsystem. So the inputs, processors, and generators will work well to produce the desired result.

In accordance with this study, argued that all processes ought to function in order to attain the ultimate objectives. Due to the input-output model, if the university facilities are fine, students with high admission points, high social economic background and good school history are expected to perform well, the lecturers and university administration are fine, which might not always be the case, and this is the shortcoming of that theory.

According to Kyoshaba (2009) all interested parties have to consider the interrelationships between sections of a network. This philosophy requires a shared goal, so that all university people get an understanding of what they are trying to do from all interested parties, a challenge that is not easy to accomplish.

The impact of a nation's level of education on its economic development and growth has motivated scholars to examine the factors that decide student academic performance in various fields of knowledge, with the goal of promoting steps or changes in education policy that reduce the high university drop-out rate revealed by the European Commission (2011) and provide well-trained students.

Many of these studies could be represented, taking as a reference the postulates of the theory of human capital, through an educational production function that characterizes the learning process of the students, related the results obtained by these (output) with a number of variables (input) that measure the effect of demographic, economic, academic and/or institutional factors.

Academic achievement is calculated by school grades in most of the previously conducted studies, and commutative GPA is more useful for assessing student academic success at university level.

The roles of education development take children's school output as a result of the inputs of parents such as the amount and quality of time they devote to their children and these are assessed by the level of education and occupation of parents, employment / unemployment status in empirical research. Many empirical studies have found a positive impact of the educational level of the parents, primarily that of the mother, although some more recent research points to the fact that the educational level impact of the mother appears to decrease at the high school and university levels. Jobs lunemployment status findings are mixed in impact on university performance.

According to human capital strategies school success at university level is often influenced by course characteristics of pre-university. Frequent movements from school to school, number of failures and the existence of breaks in primary and secondary school trajectories tend to have a perverse effect on performance.

According to Light, R. (2001), as reported those schools, colleges and universities are the most valuable assets for any educational institution without students. The academic success of the students plays an important role in generating the highest quality graduates, who will become the country's great leader and manpower responsible 
for the economic and social growth of the country.

The performance of students at University Teknologi Mara has been based on their Cumulative Grade Point Average (CGPA). Some of the students would not be able to complete their study in the final semester because in each semester they had failed some subject which leads to their being dismissed. This scenario occurred due to many factors such as characteristics of the family, self-efficacy and features of the university.

According to McCoach et al. (2006), the student achievement has been associated with a number of maleable school, teacher, and parent features factors. Farooq et al, (2011) also reported that the level or family characteristics of parental education and family socio-economic status (SES) have positive associations with the standard of achievement of the student based on the results of his study on English and Mathematics subjects.

According Mlambo (2011), the three elements correlated with academic achievement are parents (family causal factors), teachers (academic causal factors) and students (personal causal factors) in most of their studies.

Merriman (2012) claimed that self-efficacy is the confidence of a person in his or her ability to act in a certain way to achieve certain objectives. Self-efficacy, however, according to Otunuku and Brown (2007), refers to an individual's belief in how well he or she can perform behaviors successfully in a given conditions.

\section{Methodology}

This section of the paper briefly discuss both methodology and econometric analysis used to investigate the major determinants that affects the academic performance of undergraduate $3^{\text {rd }}$ year facility of business and economics students of University of Gondar in 2019 and the data applied for this study is primary data collected from randomly selected sampled graduating class students though questionnaire.

\subsection{Data types and sources}

This paper applies both descriptive and econometric analysis on primary data collected through the technique of questionnaire from graduate students of the college.

\subsection{Econometric Model Specification}

In this study students' academic performance as measured by CGPA is specified as a function of qualitative variables like sex as male or female, access to computer as yes or no, and qualitative variables such as age, students income, and the number of hours spent on for studying.

The model is one of the discrete choice models which is the Logit model by classifying the students CGPA in to two broad categories of less than and greater that or equals to three. By introducing the constant term, the value of the dependent variable without the effect of the independent variables, the coefficients of the independent variables which shows the sign and magnitude of the effect on independent Variables on the dependent one and the error or the disturbance term which will capture the effect of variables which have impact on the dependent variable but not included in the model, the model is specified as follows:

$C G P A=\beta 0+\beta 1 H S M+\beta 2 D G E N+\beta 3 D A C+\beta 4 S E F+\beta 5 D H T+\beta 6 M I N+$ error $=X B+$ error then CGPPA $=\frac{e^{X B}}{1+e^{X B}}$ following the logstic regression function

Where: CGPA $=$ cumulative GPA $=\left\{\begin{array}{l}1, \text { if } \geq 3 \bullet 00 \\ 0, \text { if }<3\end{array} \quad\right.$ DAC $=\left\{\begin{array}{l}1, \text { for Yes } \\ 0, \text { for No } \\ 0, \text { for Male Female }\end{array}\right.$

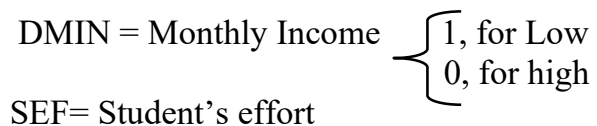

$\mathrm{HSM}=$ hours spent of social media

\subsection{Description of variables and expected results \\ Dependent variable}

Students cumulative CGPA: it is the average annual grade for all years that the student has attended as evaluated exam results assigned to be one and zero.

Independent variable

HSM: is the number of hours that the students spent on social media per day. It is taken on average and expected that their school performance will be negatively affected by this variable.

Sex: it is the male female identification of the students and male student are expected to perform more that their female counter parts.

Access to computer: as student's access to computer increases and they use it for educational purpose it is 
expected to improve the performance of the student. In this paper this variable doesn't include respondents who have access to computer but use for non-educational purpose. (Such as watching a movies and using face-book) Monthly income of student's: the amount of money transferred from parents to students will affect negatively or positively depending on the students use of money.

Student's effort: effort, in this paper, is the number of hours that students devote to study per week. It is expected to have positive impact on the performance of the student.

\subsection{Results and Discussions}

\subsubsection{Descriptive Analysis}

This section is mainly concerned with descriptive analysis result of the data and interpretation of analytical findings. The descriptive analysis covers mean, median, proportion and standard deviation to explain the features of the explanatory variables. In addition to the measure of central tendency, the descriptive analysis includes maximum and minimum.

\begin{tabular}{lllllll}
\hline Variable & Obs. & Mean & Median & Std. Dev. & Min & Max \\
\hline GENDER & 112 & 0.585 & 1.000 & 0.4939585 & 0.000 & 1.000 \\
$\boldsymbol{H} \boldsymbol{S} \boldsymbol{M}$ & 112 & 10.3 & 20.0 & 4.277083 & 5.0 & 17.0 \\
$\boldsymbol{H} \boldsymbol{M}$ & 112 & 0.54 & 1.000 & 0.4996481 & 0.000 & 1.000 \\
$\boldsymbol{A} \boldsymbol{A} \boldsymbol{C}$ & 112 & 0.47 & 0.00 & 0.5003516 & 0.000 & 1.000 \\
$\boldsymbol{S E F}$ & 112 & 0.635 & 1.000 & 0.4826383 & 0.000 & 1.000 \\
\hline
\end{tabular}

Table 3.1 Descriptive statistics

Source: own computation using stata

As can be referred from the above table, the average daily hours spent on social Medias for the sample is 10.3 with respective minimum and maximum values of 5 and 17 hours. The proportion of males to females is 29:2 signifying a higher percentage of males. On average $54 \%$ of the respondents were from the countryside and the remaining 46\% were from urban. This shows that the majority; among 112respondents; have rural origin. The monthly income students share from their family, on average, is higher with standard deviation of 0.5003516 . As can be seen in table 1, the minimum time student spend on studying on average is about 104 per week with standard deviation of 0.4826383 . In addition to this to this $93.1 \%$ of the respondents says that tutorial can really improve the academic status of students and increasing number of tutorial classes can increase the students cumulative GPA by higher magnitude.

\subsubsection{ECONOMERIC ANALYSIS}

\begin{tabular}{|c|c|c|c|c|}
\hline Variable & Coefficient & Std. error & Z value & $\operatorname{Pr}(>|z|)$ \\
\hline (Intercept) & -0.14504 & 0.82906 & -0.175 & 0.861123 \\
\hline GENDER & 0.81652 & 0.32643 & 2.501 & $0.012372 *$ \\
\hline HSM & -0.05508 & 0.03796 & -1.451 & 0.146801 \\
\hline$H T$ & 0.45563 & 0.35793 & 1.273 & 0.203025 \\
\hline$M I N$ & -0.29428 & 0.35501 & -0.829 & 0.407140 \\
\hline$A C$ & 0.38952 & 0.34315 & 1.135 & 0.256321 \\
\hline SEF & 0.03877 & 0.01032 & 3.758 & $0.000171 * * *$ \\
\hline \multicolumn{5}{|c|}{$\begin{array}{l}\text { N.B Significant codes: } 0 \text { '**' } 0.001 \text { '**' } 0.01 \text { '*' } 0.05: 0.1 \\
\text { (Dispersion parameter for binomial family taken to be 1) } \\
\text { Null deviance: } 269.20 \text { on } 30 \text { degrees of freedom } \\
\text { Residual deviance: } 242.75 \text { on } 193 \text { degrees of freedom } \\
\begin{array}{l}\text { AIC: } 256.75 \quad N=112 \\
\text { Number of Fisher Scoring iterations: } 4\end{array}\end{array}$} \\
\hline
\end{tabular}

Table 3.2

Source: own computation

The result of regression analysis indicates that cumulative average grade point in this paper is dependent variable. Level of significant are marked with asterisks where $5 \%$ significant coefficient marked with one asterisks while those at $10 \%$ are marked with two asterisks. Variable gender explains only $5 \%$ of the variation in the dependent (CGPA) variable. The variable found to be statistically significant for our study were gender where the gender gap is in favor of males students, and students effort measured in terms of time/hour spend on studying per week whereas the student who spend more hour in studying outperform than those who do not. In our study we found that male students have better chance of achieving higher grades. Although there is no research basis for it, University of Gondar has an implied policy which is based on affirmative action to upgrade female students through one to five cooperative ways. This has now been confirmed by the study that the gender gap is in favor of male students.

There is also significant difference in academic performance of students with computer access and those without access to PC. Those that access computer have a better chance than their counter part to score higher 
grades. But in our study we found that access to computer determines student's performance insignificantly. It is also observed that students who are younger perform significantly better than older students. In addition, variables such as home town (origin) and monthly income have insignificant effect on the dependent variable, academic performance of students.

\subsubsection{Estimation Results with Marginal effect}

\begin{tabular}{|c|c|c|c|c|}
\hline Variable & Marginal effect & Std. Err. & $\mathrm{Z}$ value & $\operatorname{Pr}(>|z|)$ \\
\hline GENDER & 0.1937041 & 0.0764408 & 2.5340 & $0.0112756 *$ \\
\hline HSM & -0.0130305 & 0.0089593 & -1.4544 & 0.1458361 \\
\hline$H T$ & 0.1078401 & 0.0844507 & 1.2770 & 0.2016162 \\
\hline MIN & -0.0696536 & 0.0839778 & -0.8294 & 0.4068619 \\
\hline$A C$ & 0.0929618 & 0.0823019 & 1.1295 & 0.2586778 \\
\hline SEF & 0.0091707 & 0.0024067 & 3.8106 & $0.0001387 * * *$ \\
\hline $\begin{array}{r}\text { N.B Sign } \\
\text { dF } \\
{[1} \\
1\end{array}$ & $\begin{array}{l}\text { des: } 0 \text { '***' } 0 . \\
\text { discrete chang } \\
\text { 'HT" "MIN" }\end{array}$ & $\begin{array}{l}0.01 \text { '*' } 0 \\
\text { nellowing }\end{array}$ & & \\
\hline
\end{tabular}

Table 3.3

Source: own computation

In this part of the paper we analyzed the effect of a change in either of the explanatory variable; age, gender, monthly income of the students and students' effort, and other variables included in our model. As can be seen in table 3, if there is a unit increment in student's effort measured in number of time/hour spend in studying, there is corresponding rise of CGPA by 0.093 holding other explanatory variables. From the study result it is observed students who actually spend more of their time in studying score higher than those who do not, this is consistent with our initial hypothesis. The other variable which explains the academic performance of the students is gender where the proportion is in favor of male students. The study indicates that male students have more chance of scoring than females students. Variables like monthly income, age, home town and access to computer have no significant effect on the dependent variable in our study.

\section{Conclusion}

This research is performed using logistic regression method to investigate the determinants of academic success of students at Gondar University. The research employed methods both descriptive and econometric. With this regard if there is a unit increment in students effort measured in number of hour spend in studying, there is corresponding rise of CGPA by 0.093 holding other explanatory variables. Moreover, student's effort is the primary determinant of student's academic performance at university level and there is a need of support for female students.

\section{REFERENCES}

Becker, Gary S., Human Capital: A Theoretical and Empirical Analysis, with Special Reference to Education (1964). University of Illinois at Urbana-Champaign's Academy for Entrepreneurial Leadership

Elinah Mandimika (2016), Determinants of students' academic performance in four selected accounting courses at University of Zimbabwe

Jacobs, Glen. (2002), Non-Academic Factors Affecting the Academic Success of Grenadian Students at St. George's University (SGU)"

Kyoshaba M. (2009), Factor affecting academic performance of under graduates at Uganda Christian University Light, R. (2001). Making the most of college. Cambridge, MA: Harvard University Press

Merriam E. (2012), what determines the students' school performance in higher institutions"

University of Zimbabwe-Institute (2009), Chartered Accountants of Zimbabwe Memorandum of Association.

Mlambo, V. (2011). An analysis of some factors affecting student academic performance in an introductory biochemistry course at the University of the West Indies. Carribean Teaching Scholar, 1, 79-92.

Koontz W. (1988), The Organizational Communication Process in Schools Günbayi, Ilhan.Kuram ve Uygulamada Egitim Bilimleri; Istanbul Vol. 7, Iss. 2 : 787-798.

Austrian University admission center (2006), Dropout Rates in Medical Students at One School Before and After the Installation of Admission Tests in Austria

University and Other Tertiary Institutions Act 2001. Acts Supplement No. 6. $6^{\text {th }}$ April, 2001. The Uganda Gazette, Volume XCIV, UPPC: Entebbe.

European Commission of human rights (2011), Relationship between Social Context, Self-Efficacy, Motivation, Academic Achievement, and Intention to Drop Out of High School: A Longitudinal Study

McCarty,C. Padgham,G. and Bennet, D.( 2006). Determinants of Student Achievement in Principles of Economics. Journal for Economics Educators, Volume 6, Number 2. [10] 
Mushtaq, I. and Khan, S.N.(2012). Factors Affecting Students' Academic Performance. Global Journals Inc. (USA). Global Journal of Management and Business Research. Volume 12 Issue 9 Version 1.0 June 2012. Online ISSN: 2249-4588 \& Print ISSN: 0975-5853

Faroug, chaudhry,shafiq,berhanu (2011) factors affecting students quality of academic performance, university of pakistan 